\title{
The Economics of Buying Complex Weapons
}

\section{Henry Ergas and Flavio Menezes}

$\mathrm{D}$ efence procurement is an important current policy issue in Australia. On one hand, there is a build-up in defence outlays as a result of the war on terrorism, our military's involvement in peace missions in our region and beyond, and changes in the threats facing Australia. Given the extra resources directed to defence, it is natural to expect that these expenses will be subjected to a greater degree of scrutiny. On the other hand, greater public scrutiny also follows from a history of major delays and cost overruns in the Collins Class submarines and the Jindalee Operational Radar Network projects. A recent media report (see http://www.abc.net.au/news/newsitems/s1058425.htm) cites the findings of a review of the Government's defence equipment projects by the Australian Strategic Policy Institute indicating a multi-billion dollar blow out in the cost of new defence equipment. According to the media report, the costs of the Air Warfare Destroyers have doubled while the costs of the upgrade of the Chinook helicopter have more than tripled.

In this paper we are concerned with the procurement of complex weapons systems. We review the major characteristics of the weapons systems acquisition process that distinguish this process from a standard regulation problem. We then discuss some of the outcomes of the acquisition process and focus on the relevance of the economic theory developed over the last twenty-five years for creating remedies to mitigate the intrinsic inefficiencies in the weapons systems acquisition process.

Specifically, a weapons system is defined as a composite of equipment employed as an entity to accomplish a military mission (such as destroying enemy installations, identifying hostile aircraft, protecting advancing infantry or surveying territory). Complex weapons systems, such as those associated with fighter aircraft and bombers, frigates and submarines, tanks and armoured personnel carriers, account for a high share of defence outlays in the more advanced economies. The process of acquiring complex weapons systems encompasses their conception, development and production. In this paper we focus on the efficiency of the acquisition process. Efficiency in this context involves organising the process of acquiring each of those systems in a manner likely to maximise the systems' net value.

Henry Ergas is Managing Director of the Network Economics Consulting Group and Flavio Menezes is Professor of Economics and Director of the Australian Centre of Regulatory Economics, The Australian National University. 


\section{The Nature of the Weapons Acquisition Process}

At first sight, the complex weapons acquisition process is simply a form of regulation: the government determines the price to cover producers' costs and to guarantee that firms in the industry maintain an appropriate level of investment. However, the complex weapons acquisition process has a number of attributes that distinguish it from standard regulatory processes, for reasons we discuss below.

There is an extent to which the difficulties that arise when purchasing complex weapon systems are common to many large civilian projects with long lead times and untested technologies, such as a new mine based on a new extraction technology (see, for example, Merrow, McDonwell and Arguden, 1988). However, in our view, the acquisition of complex weapons systems is in a category of its own in terms of the challenges it imposes given the nature and extent of the uncertainties, the fact that the buyer is the government and that there are several within-government incentive issues, the characteristics of the seller including the market structure in the industry, and the special characteristics of the contractual relationship between the buyer and the seller.

\section{The product}

Considered as a product, complex weapons systems are characterised by the substantial technical difficulties involved in their conception, development and production. These difficulties arise mainly from three sources (Peck and Scherer, 1962). Firstly, bringing each system into operation involves a large number of distinct technical problems, associated with the large number of subsystems each such system involves. Simply because of the sheer number of separate technical issues involved, the probability of encountering substantial problems in at least some aspects of the system must be high. Secondly, the difficulties involved in solving each such problem are greatly complicated by the inter-dependence between technical issues, as the subsystems need to inter-work. Finally, further constraints on system design and redesign arise from the need for reliability under highly challenging conditions.

Peck and Scherer (1962) refer to internal uncertainty as that arising from the complexity of the technical issues involved in conceiving, developing and producing weapons systems. They also refer to external uncertainties as those arising from a shift in the demand for a system resulting, for example, from a change in the geopolitical scenario that might result in a change in the nature of the external threat facing a nation. Given the very long lead times involved in weapons system procurement, these uncertainties in practice imply that it is not possible to fix the main parameters of a system — be it in terms of its outputs or in terms of its inputs - with any degree of precision prior to incurring what may be considerable outlays.

It would be tempting, but often misleading, to think that these uncertainties can be resolved at the conception and development stage. In the jargon of information economics, most weapons systems are 'experience' rather than 
'search' goods - their attributes only become fully known in use. As a result, the need for ongoing adaptation persists, so that system parameters generally change, in some cases very substantially, during the acquisition process.

The need for adaptation is accentuated by the fact that because of weapons systems' complex nature, long lead times are involved in the acquisition process - with 8 to 12 year lags being typical, and even longer lags being observed in individual cases (Peck and Scherer, 1962; Baron, 1993). Additionally, weapons systems are typically long lived, with lifetimes that can extend over several decades. The planning cycle for a system, covering the period from serious commitment to its acquisition through to the time of decommissioning, therefore spans many years.

As circumstances will inevitably change over that period, including during the time of initial development, weapons systems are exposed to substantial risk of obsolescence, that is, of loss in value (in terms of their ability to accomplish their military mission) due to the appearance of superior alternatives. Almost inevitably, responding to obsolescence involves allowing some degree of system redesign during development. It also involves providing scope for refurbishment or modification during the system's operating life. The response to obsolescence therefore increases the extent to which weapons systems are evolving products that cannot be well specified in advance.

The final characteristic that differentiates weapons systems from other regulated products refers to the relationship between the required substantial sunk costs and the nature of the risks faced by producers. Although the precise outcomes from a weapons acquisition process cannot be readily determined in advance, substantial costs need to be incurred for a system to proceed to the production stage. Usually, a very large share of these costs are specific to the system at issue and need to be sunk prior to volume production - 'first costs', are in other words, very high (first costs being the costs that need to be incurred to deliver the first unit of output).

\section{The buyer}

Unlike in the electricity, gas, telephony, transport or health sectors, the regulator and the buyer of weapons systems are the same agent. This poses additional risks to the producers of weapons systems. For example, governments are distinguished by their limited ability to commit. In democratic systems such as Australia's, governments face constraints on the degree to which they can bind future governments. Even within the term of any given government, the annual nature of most budgetary processes reduces the scope for spending programs to be 'locked in', though governments have made greater provision for multi-year commitments in weapons procurement than in other areas of public expenditure.

The difficulties the seller faces in predicting the behaviour of the buyer, and hence gauging the risk that behaviour creates, are accentuated by the fact that governments are not unitary actors. Rather, the governmental process involves a range of players, from the armed services through to finance and treasury 
departments and the legislature, whose views and interests will differ, and whose power may vary substantially over time. The civilian-military relationship, in which the weapons acquisition process is embedded, involves all the complexities of principal-agent interaction, with extensive game playing (for example, between the armed services, their civilian controllers and treasury and finance departments) whose outcomes, as circumstances change, are often difficult to predict (Feaver, 2003).

Rogerson (1994) uses the expression 'incentives within government' to refer to those incentive issues that arise from this complex relationship between the various government actors involved in the weapons acquisition process resulting from the need to delegate authority. As Rogerson points out, unlike the relationship between the board of directors and a manager of a private firm, where there are objective (but imperfect) performance measures like profits and stock market value, there is no straightforward objective measure of the bureaucracy's performance in weapons acquisition.

Indeed, partly as a function of this 'incentives within government' problem, institutional change is a common event in most defence acquisition processes around the globe. For example, in the Australian context, the government engaged Malcolm Kinnaird, Len Early and Bill Schofield in December 2002 to review the procurement process of major defence acquisitions. This followed the creation of the Defence Materiel Organisation (DMO) in 2000 and a series of changes over the last three years. The Kinnaird Report (Kinnaird, Early and Schofield, 2003) made a series of recommendations that were broadly accepted by the government. Perhaps the most significant recommendation is the establishment of the DMO as a prescribed agency financially separate from the Department of Defence. Of course, the implementation of this separation will require the full development of a client-supplier relationship between the DMO and the defence forces. The actual effects of this separation might take a few years to eventuate.

In conclusion, notwithstanding the continued attempts at improving governance and at addressing the 'incentives within government' problem, even if a single fully rational buyer were to exist, inefficiencies would remain as the seller of weapons systems would still face a buyer who is a monopsonist and not fully capable of entering into credible pre-commitments. Sellers are consequently exposed both to monopsony power and to the risk of the buyer acting opportunistically - that is, taking advantage of changing circumstances to increase its share of the benefits from supply.

The seller

Although there are many suppliers of weapons systems internationally, even the largest economies have only a few domestic firms capable of acting as prime contractors for major systems. To the extent to which there is a requirement for domestic firms to play an important role in weapons programs, the range of competing sellers will be limited. 
The extent of competition in supply is also limited by learning effects. More specifically, experience, defined as previous participation in similar programs, appears to have a significant impact on supplier costs and capabilities (see, for example, Lorell, Sanders and Levaux, 1995). Since few major systems of any given type are ever produced, the number of firms with the experience needed to be competitive is likely to be small.

Additionally and perhaps even more importantly, within-program learning reduces the ability to shift suppliers in the course of a program. To begin with, the original contractor usually has specialised know-how, skills and facilities acquired in the program's early stages which can be duplicated by another firm only at the cost of considerable time and expense. Moreover, reliance on concurrent performance of development and production work to reduce lead times generally requires a degree of organisational continuity, at least into the early stages of production contracts. Once selected, the original contractor therefore faces limited competition in terms of subsequent supply and several studies (Peck and Scherer, 1962; Fox, 1988) report that the US Department of Defence has been reluctant to terminate even very poorly performing contractors because of the high costs of shifting to new sources of supply.

As well as facing limited competition, suppliers are to some extent shielded from full monitoring by buyers. There is, in other words, scope for moral hazard, that is, for suppliers to act in ways which generate a benefit to the supplier which is less than the costs they impose on the buyer. Under incomplete information, and even in the absence of moral hazard, it is well-known that the outcome of this 'bilateral monopoly' game is inefficient (Chatterjee and Samuelson, 1983). The moral hazard can take several forms, of which the most important are underinvestment in cost reduction, 'scrimping' on quality improvements which will reduce costs in periods in which the contractor does not bear cost responsibility (but increase costs subsequently), and an inadequate level of investment in, or disclosure of, innovations that are of net social value.

In the jargon of principal-agent models (see generally, Bower, 1994), the scope for moral hazard in the weapons acquisition process arises from asymmetric information about costs and quality (information known to the seller but not the buyer about opportunities to reduce costs or improve quality) and limited cost and quality verifiability (constraints on the degree to which the buyer can ascertain the actual costs of the system or fully assess its quality at the time of delivery). These features of the seller's position then make a range of investments noncontractable.

As a result, the seller is usually in a position both to exercise some degree of market power (reflecting the constraints on competition) and having secured a contract, to act in ways inconsistent with joint value maximisation under that contract.

As a practical matter, it is important to note that there is rarely, if ever, a single seller in a major weapons acquisition program. Though programs will usually have a prime contractor, almost all major programs involve a myriad of distinct entities, including sub-system firms, overflow producers, parts suppliers 
and makers of specialised materials. The Collins Class submarine program, for example, involves over 1500 design and construction sub-contracts (The Australian National Audit Office, 1997). These subcontractors were responsible for 80 per cent of the work associated with the program (Parliament of Australia, Joint Committee of Public Accounts and Audit, 1999). Further important difficulties arise from the fact that outcomes depend on the coordinated conduct of these entities, each of which experiences only part of the costs and benefits of its actions.

\section{The relation between the buyer and seller}

Because the buyer is essentially a monopsonist, and the seller (at least once the program is underway) has a degree of monopoly power, the governance of the relation between buyer and seller centres on the contract between them, rather than on any scope for each to turn from the other to alternative partners in exchange (as would happen in a competitive market).

This primacy of bilateral governance, and hence of 'voice' relative to 'exit' as the main means of controlling performance and outcomes, is made all the more important but also more difficult by the need for each party to incur substantial costs specific to the program at issue and non-recoverable outside that program. The sheer length of time for which the parties are effectively 'locked in' to each other and hence for which the relationship must last only makes the contract between the parties all the more important.

There are, however, substantial limits on how efficient the contract between the buyer and the seller can be as a means of governing their long-term interdependence. In particular, given the uncertainty inherent in the nature of the product, the contract between the buyer and the seller is necessarily highly incomplete. In practice, incompleteness is accentuated by the inability of the buyer to enter into fully credible commitments with respect to its future conduct, and by the difficulties involved in verifying contract performance.

As contract incompleteness increases risk, it must, if left unchecked, increase costs and reduce contracting efficiency (see generally, Williamson, 1975). Contract incompleteness creates a risk of opportunistic conduct, in which parties, faced with changing circumstances, either threaten to 'work to rule' (thus reducing the aggregate value of the project) or as the price of accepting contractual modifications, seek to increase their share of any surplus from the project. The Prescott-McIntosh review of the Collins Class submarine program instances this in a striking way. It notes that since the program's specifications were set in 1984:

... technologies have changed, the region has changed and Defence's ambitions for the boats have changed accordingly, but there has been no sensible mechanism for incorporating such changes into the contract (Commonwealth of Australia, 1999:14).

Faced with this situation, the prime contractor, the Australian Submarine Corporation (Commonwealth of Australia, 1999:15): 
... has no motivation to provide more than what it interprets as its contractual obligations, especially when the Commonwealth has established it will not pay more than the original contracted price...[However, the Project Office] acting on behalf of the Navy... is concerned that anything other than very minor amendments to the contract could let the prime contractor 'off the hook' and lead to substantial blow-outs in time and cost.

Contract incompleteness also induces the parties to engage in what may be wasteful conduct to reduce the risk associated with renegotiation. For example, parties might seek extensive and rigid rules, thus providing them with a degree of veto power over any change in the contract's terms. This merely exacerbates the difficulties involved in adjusting to changing circumstances, but it promises each party an increased ability to protect its interests when contract modifications need to be made. This effect has been documented, for example, in the Collins Class submarine project (Parliament of Australia, Joint Committee of Public Accounts and Audit, 1999).

Another frequently studied example of behaviour aimed at reducing the risk posed by contract incompleteness involves military buyers who engage sunk costs too quickly to lock governments into programs they might otherwise be tempted to terminate, or substantially scale back (Rogerson, 1993). By front-loading costs, the armed services reduce the attractiveness to governments of program cancellation, since cancellations only allows few costs to be avoided and increase the political costs associated with cancellation, as in the event of cancellation, the funds so far expended will appear to have been entirely wasted. Interestingly, in the Collins Class submarine project, as of 31 March 1999, Defence had spent 93 per cent of the expected total project 'for which there are five boats in the water, but none performing anywhere near adequately' (Commonwealth of Australia, 1999).

In short, we can describe the relation between buyer and seller as a bilateral monopoly. Thus, the governance of their interaction hinges on the contract that binds them, rather than on any scope to turn to alternative exchange opportunities (as would happen in a competitive market). Given that the product required is difficult, if not impossible, to fully specify in advance, contracts are necessarily incomplete. As a result, ongoing contract adaptation is required, but that adaptation increases the risk each party bears. Parties anticipate that risk and seek to protect themselves from it, including by engaging in conduct which exacerbates the underlying problem.

\section{Perceived Outcomes}

An obvious difficulty that any assessment of the outcomes of the weapons acquisition process must address is that of defining performance. Additionally, it is important to distinguish ex post assessment, which may be distorted by reliance on '20/20' hindsight, from the evaluation of actions on an ex ante or interim basis. 
In terms of assessing program outcomes, three dimensions seem most important. First, the military value of a system depends on its quality, which may be described in terms of features such as its speed, destructive force or accuracy. Second, the value of a system also depends on the time at which and for which the system is available. Third, the cost of a system, both at initial deployment and in terms of recurrent resource requirements, needs to be balanced against quality and timeliness.

Successive evaluations of weapons acquisition programs have largely confirmed the early findings that programs tend to perform extremely poorly in terms of cost, moderately poorly in terms of timeliness and ultimately at least, relatively well in terms of quality (Peck and Scherer, 1962). These outcomes are consistent with those observed in non-military projects of high technical sophistication: careful comparisons find that it is not easy to conclude that weapons programs perform 'more poorly' than their closest civilian and private sector counterparts (Peck and Scherer, 1962; Merrow, McDonwell and Arguden, 1988). In both cases, large-scale, technically advanced, programs involve substantial cost over-runs and delays.

That is, when technical difficulties are encountered, it seems that it is mainly cost that 'gives'. In other words, decision-makers, faced with the problems that inevitably arise, systematically tend to trade-off higher cost and somewhat delayed delivery so as to ensure that quality objectives are met.

Consistent cost overruns seem consistent with a pattern in which there are soft budget constraints, that is, in which there is scope to renegotiate costs subsequent to the discovery of factors (most obviously, technical difficulties) that compromise the viability of the initial cost assessment (Maskin and $\mathrm{Xu}, 2001$ ). The expectation that budget constraints are soft then has two consequences.

The first is a tendency to systematically underestimate costs, most notably so as to advance the prospects of the program in its competition with other (military and non-military) uses of resources. Weapons programs are of course, not alone in this respect - systematic under-estimation of costs has been observed in many areas of public administration (see, for example, Flyvbjerg, Holm and Buhl, 2002) and in those aspects of private sector activity where principal-agent problems are most acute.

The second consequence of soft budget constraints is that suppliers, faced with costs that are underestimated to begin with, have less incentive to invest in cost reduction efforts. In contrast, especially in mission-critical systems, failures to achieve intended quality likely will seriously harm supplier reputation, and hence considerable resources will be devoted to avoiding such failures from occurring.

In summary, while some degree of cost uncertainty is inherent in technically complex programs, the extent and pattern of the cost variances observed in weapons programs suggest that it is not only random error in cost estimates that is at fault. Rather, the presence of soft budget constraints has imparted a systematic direction to the error, inducing recurring cost overruns. 


\section{Remedies}

At least since the mid-1960s, cost-plus contracts, allocated and/or implemented under conditions of limited competition, have been widely viewed as a central element in allowing the outcomes noted above to prevail (McNaugher, 1989).

More specifically, in the absence of the disciplines (including through the scope for benchmarking performance) that come from competition, cost-plus contracts provide limited penalties for cost overruns, while also providing few rewards for aggressive cost containment. To the extent to which the allowed rate of return under such a contract exceeds the supplier's weighted average cost of capital, there will be incentives for cost padding, with the use of an input mix that is too capital intensive (the Averch-Johnson effect). If capital intensity and system quality are correlated, there can also be 'gold plating'; in the sense that quality will be over-provided.

As a result, attempts at improving the efficiency of the weapons acquisition program have involved placing greater reliance on competition and/or moving away from cost reimbursement contracts. Experience shows however, that there are severe limits to both of these remedies. More recent reform efforts have therefore involved a more complex mix of measures.

\section{Competition}

In technologically dynamic industries, competition has both a rivalry effect and a portfolio effect. The rivalry effect refers to the impact that the threat of being displaced or the prospect of displacing rivals has on suppliers' incentives to perform. The portfolio effect refers to the impact the concurrent conduct of a range of independent development efforts has on the probability of identifying, in a timely and cost-effective way, the optimal approach. The extent of these effects, and of the net benefits that flow from them, depend both on the degree and on the type of competition.

Competition can occur either 'in the market' - in the sense of involving concurrent supply by several independent firms — or 'for the market', through the competitive allocation of an exclusive contract to supply (as in franchise bidding for a natural monopoly). This conventional kind of competition 'in the market' cannot occur, at least on any substantial scale, for complex weapons systems because of the risk of 'hold up': it would be highly risky for potential suppliers to engage substantial product development, testing and engineering prior to having obtained some degree of buyer support. As a result, the 'architectural' issue buyers need to address is how many sellers they want to bring into the market for any particular system, and whether to retain the parallel presence of those sellers throughout the acquisition process or only for certain phase(s) in that process.

Typically, the fixed costs involved in weapons acquisitions programs are high. Full scale competition 'in the market' involves duplicating these fixed costs, which is often prohibitive. This is all the more the case given that the gains which appear to come from weapons system competition in terms of greater supplier 
'keenness' are not so great as to outweigh the cost penalty duplication entails (see, for example, Birkler, Dews and Large,1990; Pilling, 1989).

As a result, full parallelism in supply (that is, the parallel presence of independent sellers throughout the acquisition process) has been very much the exception. The most widespread form of procurement architecture uses parallel efforts in the earlier stages of acquisition (generally system development), with production then being allocated to a single source, perhaps through some kind of competitive bidding.

In practice, however, such 'design competitions' can only work effectively where the fixed costs involved in design are not very large; where the know-how generated in the development phase is readily transferred between organisations; and where close integration, much less concurrency, isn't needed between design and production. These conditions are frequently not met. Even when they are met, the extent to which 'design competitions' really exercise competitive disciplines must largely depend on how effective the subsequent competition 'for the market' proves to be, as it is the post-design stages that account for the bulk of costs.

If competition 'for the market' is to be effective, there need to be at least two potential competitors. This may not be the case in relatively small economies such as Australia's if local content goals are being pursued. Even if there are two or more competitors, competition 'for the market' brings its own distortions. Depending on the hardness of budget constraints and of contractual commitments more generally, firms will have incentives to 'bid low' (be it by understating costs or by overstating quality), with a view to subsequent contract renegotiation. The fact that the winning tenderer will be the one that is most optimistic (about costs, timeliness and quality) adds a dimension of the 'winner's curse' to the outcomes of the competition.

These points imply that the efficiency of competition 'for the market' depends to a substantial extent on the efficiency of the contractual arrangements that will govern the relation between buyer and seller once the competition closes. If there are soft budget constraints, or if quality is non-verifiable (in whole or in part), competition 'for the market' will not remedy the poor outcomes noted above - indeed, it can make them more severe (for example, if it increases the incentives for cost and quality misstatement).

This does not mean that competition 'for the market' is of no utility. It can serve an important purpose as a means of soliciting seller investment in proposals. For example, the US Department of Defence uses a procedure where there is a competition at the design phase with the winner receiving some economic profits as a result of being awarded a sole source production contract. Rogerson (1994) provides a discussion of the 'prizes for innovation' theory and practice.

Additionally, where there are large numbers of potential suppliers, it provides a structured framework for supplier selection. For example, the US General Accounting Office (1999) estimates that, by using competitive sourcing, the Department of Defence will have saved an estimated US\$6 billion in the period 1997-2003. Moreover, when standard goods and services are being bought, the 
sheer size of the defence forces means that it can use its monopsony power to extract more rents from the sellers via a more sophisticated auction design. For example, the use of reverse auctions (the equivalent to an English auction in the procurement context) by the UK Ministry of Defence will make cost savings in excess of 65 per cent (about £750,000) when purchasing around 3 million packets of tissues (see http://www.ogcbuyingsolutions.gov.uk/information/releases/ release_200803.asp).

Finally, when independent suppliers compete and the auction design is efficient, the prices they offer will pass back to the buyer any rents (in excess of the second lowest cost) that the suppliers could hope to make from the contractual imperfections - in other words, the gains from any post-contract supplier market power will be capitalised into the competing offers, effectively insuring the buyer against the exercise of that market power. However, the inefficiencies associated with those contractual imperfections will persist.

Considerable attention has been paid to the scope to retain some degree of potential competition 'in the market' even once the contract 'for the market' has been allocated. More specifically, the threat of second-sourcing, of turning from the chosen supplier to an alternative, has been seen as a way of injecting continuing discipline into the supply process. The circumstances in which the threat of second-sourcing is credible are relatively tightly defined. It must be feasible to transfer some or all of supply to an alternative source, which may be extremely costly if substantial site- or supplier-specific fixed costs are involved in supply.

The impact of the threat of second-sourcing is complex. If there is substantial rivalry for the initial contract, any rents from contractual imperfections will be bid away, as they will be built into the offers made. The threat of second sourcing merely increases the risk of opportunistic behaviour by the buyer and hence the initial bid price must rise (for given levels of quality and timeliness). Thus, assuming effective competition for the initial contract, there cannot be an overall gain in efficiency (Anton and Yao, 1987; Riordan, 1993). That is, overall, secondsourcing is likely to make at most a relatively marginal contribution to the extent of competitive disciplines, at least in small markets like Australia's.

A further option for increasing the extent of competition is that of reducing the spacing between successive generations of weapons systems. If new systems are developed while the prior generation still has some years of service potential remaining and the realistic option of having its service potential further extended, then there can be a degree of competition between the new system and its predecessor. Obviously, this involves a willingness to bring system renewal forward in time, to enhance the degree to which the new system and its predecessor are effective substitutes. In the context of the Collins Class submarine program, in contrast, the Oberon class was at a point where there was only one operational boat (Commonwealth of Australia, 1999).

In short, competition, be it 'in the market' or 'for the market', is far from being a panacea. High fixed costs impede the former. As for the latter, its efficacy depends to a substantial degree on the efficiency of the contracts between 
the buyer and the chosen seller. To the extent to which these contracts are necessarily incomplete, competition for the right to be the chosen seller cannot resolve the distortions incomplete contracts give rise to, though it can limit the amount of excess seller profits these distortions might otherwise create.

\section{Cost reimbursement versus fixed-price contracts}

The move away from pure cost reimbursement contracts to contracts based on fixed prices is another important element in attempts to increase the efficiency of the weapons acquisition process. Underpinning this move is the belief that pure cost reimbursement contracts create incentives for moral hazard, in the form of inducements to pad costs or to not invest to an optimal degree in efforts at cost reduction. In contrast, fixed-price contracts will provide 'high powered' incentives for cost reduction, as the firm will retain any profits made by reducing costs.

In practice, the incentives provided under fixed-price contracts may not in fact be as 'high powered' as all that. There are two aspects to this. The first arises when the information the firm generates in one period affects outcomes in subsequent periods - for example, when the price offered to the firm in subsequent periods is reduced in line with information about achieved cost reductions in the current period. This 'ratchet effect' naturally dulls the firm's incentive to achieve cost reductions. The second and practically more important effect arises when adverse consequences eventuate - say when costs prove much higher than originally expected. If governments are unwilling to allow supplier bankruptcy to occur, and a 'bail out' occurs, then the soft budget constraints will not in fact have been 'hardened.'

However, even if it is assumed that the buyer can credibly commit to a fixed price, so that the cost-reduction incentives are indeed 'high powered', it does not follow that fixed-price contracts are efficient. Three broad sets of argument are relevant here.

The first is that fixed-price contracts may lead to an inefficient, and ultimately unsustainable, allocation of risk. Imposing a fixed price shifts substantial risk on to the seller, without it being at all clear that the seller is best placed to manage that risk. In effect, governments, with their ability to pool risk across many competing sources of income, will usually have greater options for efficient insurance than would be available to private suppliers. If the risk is placed on the supplier, then a corresponding (and inefficiently high) risk premium will need to be built into the contract price. Under these circumstances, reliance on fixed-price contracts will increase rather than reduce prices over the longer term.

Second, a fixed-price contract may induce distortions in the allocation of effort. The essence of the incentive provided by the fixed price is that the firm secures the entire return on investment in cost reduction. However, other investments the firm might make are not equally rewarded and may not be 
separately contractible or in fact contracted for. The firm will then under-invest in these other aspects of performance.

Third, fixed-price contracts generate their own forms of opportunistic behaviour. The buyer under such a contract has strong incentives to exploit opportunities to increase the seller's costs (subject to not driving the seller into liquidation), for example by interpreting product specifications in ways that shift costs onto the seller. At the same time, particularly when adverse circumstances occur (for example, costs prove to be higher than expected), the seller has incentives to seek to escape from legal liability for supply.

Like competition, fixed-price contracts are therefore no panacea. They put a high value on apparent certainty in terms of the 'headline cost', but that certainty may well be obtained at the expense of considerable inefficiency.

\section{Other options}

Given the limits of the reform proposals set out above, attention has more recently focused on other options for making the acquisition process work better. While these options are extremely diverse and to some degree overlapping, it is convenient to consider them under three broad headings: the 'production function' for system acquisition; contract design; and the wider environment for the weapons acquisition process.

\section{The production function}

As with other products, the weapons acquisition process involves a production function that relates inputs (the resources used in the process) to outputs (the goods and services obtained) (Peck and Scherer, 1962). There are reasons to believe that acquisition processes have involved a degree of inefficiency both in terms of outputs and inputs.

On the output side, there appears to have been a tendency, evident in projects such as the Collins Class submarine and the Jindalee Operational Radar Network, to seriously underestimate the cost of seeking high levels of technical sophistication. It is well-known that costs, and the variance of costs around the expected cost level, rise rapidly with system complexity (see, for example, President's Blue Ribbon Commission on Defence Management, 1986; McNaugher, 1989). Specification of simpler systems, less loaded with complex requirements, could well allow substantial cost savings.

On the input side, there is a longstanding concern about whether the appropriate level and mix of human capital is devoted to major system procurement (Peck and Scherer, 1962). In particular, far greater investment is made in the technical aspects of weapons acquisition than to the management of the acquisition process itself. Staffing of the commercial aspects of the acquisition process often involves significantly lower levels of skill (and correspondingly, pay) than seem sensible in view of the amounts at stake (Kelman, 2003; see also, in respect of the Collins Class submarine project, Parliament of Australia, Joint Committee of Public Accounts and Audit, 1999). 
In short, less technically demanding projects, better staffed on the commercial side, could well allow for the better use of resources.

\section{Contract design}

There are recent trends towards using a hybrid approach to contract design (see, for example, Drezner and Leonard, 2002; Ingols and Brem, 1998; Lorell et al., 2000). These approaches have three common elements.

First, target outputs are specified and suppliers are given greater control over the technical means by which those outputs are achieved. This in turn requires extending the supplier's responsibility to later phases in the product's life cycle, to ensure that technical specifications are not chosen to shift costs from the production phase to the operating phase.

Second, a phased approach is used for pricing. In particular, the system development stage remains subject to a cost-reimbursement approach. However, even during system development, suppliers are made aware of a price ceiling, beyond which the system at issue will not be procured. This 'must cost' cap serves to render explicit (both to the system developers and to the community) the reservation price associated with the system's expected military value. If the cap is not met, the project is cancelled. If the cap is met, then production price commitments are entered into for initial production lots. These price commitments will reflect cost experience to date and anticipated rates of cost reduction (through learning or other scale effects).

Price paths are also sought for production runs beyond the initial lots. These price paths are not binding, in the sense that should the buyer seek to exercise the option to obtain these subsequent lots at that price, the seller may at that stage seek a different price. However, the buyer then has the option of securing supply from the seller on a cost-reimbursement basis. In other words, the buyer has a call option either to buy at the bid price or to buy at the cost-reimbursement price. The seller, on the other hand, is not assured of a put option symmetrical to the rights vested in the buyer, but is assured that if the buyer does procure units subsequent to the initial lots, the price for those units will not be lower than specified in the seller's successful non-binding bid. Separately, incentive payments are provided if the system's performance exceeds expectations.

Third, greater weight is placed in seller selection on sellers' past performance. This allows suppliers to secure an explicit return on investment in reputation and helps convert the acquisition process into a repeated game. Sellers are thereby discouraged from engaging in short-term, opportunistic, conduct, as the penalties associated with that conduct are increased.

\section{The context in which acquisition occurs}

Finally, increased attention has been paid to shaping the context in which acquisition occurs. This perhaps inevitably involves a range of relatively 'soft' variables, only some of which have been studied in a formal way by economists. Two such variables stand out. 
The first is trust, or what might be more broadly referred to as the social context of the procurement relationship. It is known that such contractual incompleteness might be least distorting when agents share a broad understanding of goals and of the norms that are acceptable in achieving those goals (see especially Kreps, 1990). This is because the shared norms and goals reduce the risk of opportunism, and hence the risk loading that affects product costs, and facilitates mutual adjustment to changing circumstances. For example, the costs of major nuclear programs appear to have been significantly lower in France, where institutional arrangements make for common socialisation of defence buyers and suppliers, than in the US or the UK (see, for example, Kolodziej, 1987).

It is not easy to identify policies that materially affect the relevant dimensions of trust and that are meaningfully within the control of acquisition authorities. However, there are reasons to believe that competition tends to undermine a perception of shared goals and norms. Most simply put, in a competitive environment, suppliers may have stronger incentives to act opportunistically, since they have less assurance that passing up opportunities for short-term gain will yield long-term rewards. Moreover, supplier investments in reputational capital may need to be written off if their relationship with the buyer comes to an end. As a result, there is a tension between subjecting suppliers to competitive pressures and seeking from them types of behaviour more commonly found in repeated games. Clearly, placing greater weight on past supplier performance as a criterion in supplier selection is one way of attempting to ease this tension.

A second dimension of the context in which acquisition occurs is monitoring. Systematic project and program evaluation by authoritative independent parties can serve a range of important functions. These include facilitating conflict resolution by acting as a neutral evaluator of conflicting claims; improving accountability and hence increasing the pressure for good performance; and drawing the lessons from acquisition experience in a timely and rigorous manner, hence allowing both more and less promising approaches to be identified sooner and more effectively.

An obvious example is the important role the Federally Funded Research and Development Corporations play in the US, and most notably RAND, the Institute for Defence Analysis and the Centre for Naval Analyses (Defence Science Board Task Force, 1997). RAND in particular has pioneered economic analysis of acquisitions programs and continues to act as an important source of rigorous research in this area.

In his study of major British procurement failures, Henderson (1977) stressed the role that the lack of transparent, early evaluation and accountability played in ensuring 'the unimportance of being right' - that is, the absence of rewards for successful decision-making and of penalties for poor decision-making. In Australia, while it is true that the Audit Office has been of obvious importance in highlighting performance issues in programs such as the Collins Class submarines and the Jindalee Operational Radar Network, no systematic, economic, evaluation of programs is carried out independently from the buyer. Additionally, past 
reports aimed at drawing more systematic assessments - most notably the then Industry Commission's review of defence procurement (Industry Commission, 1994) - are outdated and did not go deeply into the economic issues involved. Thus, a greater emphasis on an independent systematic economic evaluation of weapons systems acquisition programs has the potential to yield some gains in terms of program effectiveness.

\section{Conclusions}

The complex weapons acquisition process is afflicted by almost al of the pathologies that prevent efficient outcomes: information asymmetry, conflicting goals, non-commensurable objectives, lack of credible commitments, within government incentive problems, all superimposed with a high degree of technical complexity and uncertainty. Developing a proper diagnosis of the reasons for the necessary imperfections associated with purchasing complex weapons systems is important, as it can help us to understand both the limits and the potential of reform proposals.

Several lessons can be drawn from the discussion above. Firstly, competition (either 'in the market' or 'for the market') and fixed-price contracts are useful tools but they will not result, by themselves, in efficient outcomes. Secondly, there seems to be scope for hybrid contracts, involving both cost-plus and fixedprice elements. One of the most important lessons arising from the economics of designing auctions and tender processes is that the details matter. This suggests that 'one-size-fits-all' approaches to procuring complex weapons systems are destined to fail and, instead, the 'right' hybrid contract has to be designed on a case-by-case basis. Finally, greater emphasis should be placed on addressing the incentives within government issue - and the financial separation of the DMO from the Department of Defence is a step in the right direction - and on encouraging independent and systematic economic evaluation of the complex weapons acquisition process.

\section{References}

Anton, J. and D. Yao (1987), 'Second Sourcing and the Experience Curve', RAND Journal of Economics 18:57-75.

Australian National Audit Office (1997), New Submarine Project, Department of Defence, Commonwealth of Australia, Audit Report No. 34, 1997-98.

Baron, D. (1993), 'Defense Procurement: Politics, Management and Incentives’ pp. 7-24 in J. Leitzel and J. Tirole (eds), Incentives in Procurement Contracting, Westview Press, Boulder.

Birkler, J., E. Dews and J. Large (1990), Issues Associated With Second-Source Procurement Decisions, RAND, R-3996-RC.

Bower, A. (1994), Essays in the Economics of Procurement, RAND, MR-462-OSD. 
Chatterjee, K. and W. Samuelson (1983), 'Bargaining Under Incomplete Information', Operations Research 31:835-51.

Commonwealth of Australia (1999), Report to The Minister for Defence on The Collins Class Submarine and Related Matters, Commonwealth of Australia, Canberra (PrescottMcIntosh Review).

Defence Science Board Task Force (1997), Federally Funded Research and Development Centres (FFRDCs) and University Affiliated Research Centers (UARCs), Office of the Under Secretary of Defense for Acquisition \& Technology, Washington, DC.

Drezner, J. and R. Leonard (2002), Innovative Development: Global Hawk and DarkStar - Acquisition Management and its Transitions Within and Out of the HAE UAV ACTD Program, RAND, MR-1475-AF.

Feaver, P. (2003), Armed Servants: Agency, Oversight and Civil-Military Relations, Harvard University Press, Cambridge, Mass.

Flyvbjerg, B., M. Holm and S. Buhl (2002), 'Underestimating Costs in Public Works Projects', APA Journal 68(3):279-95.

Fox, J. Ronald (1988), The Defense Management Challenge: Weapons Acquisition, Harvard Business School Press, Cambridge.

General Accounting Office (1999), 'DOD Competitive Sourcing', Report GAO/NSIAD99-46.

Henderson, P. (1977), 'Two British Errors: Their Probable Size and Some Possible Lessons', Oxford Economic Papers 29(2):159-205.

Ingols, C. and L. Brem (1998), Implementing Acquisition Reform: A Case Study on Joint Direct Attack Munitions (JDAM), Defense Systems Management College, Washington DC.

Industry Commission (1994), Defence Procurement, Report No. 41, AGPS, Canberra.

Kelman, S. (2003), 'Remaking Federal Procurement', Working Paper No. 3, Visions, The John F. Kennedy School of Government, Harvard University.

Kinnaird, M., L. Early and B. Schofield (2003), 'Defence: Procurement Review 2003', The Kinnaird Report. Department of Defence, Canberra, available at http://www.defence.gov.au/publications/dpr180903.pdf

Kolodziej, E. (1987), Making and Marketing Arms: The French Experience and Its Implications for the International System, Princeton University Press, Princeton, New Jersey.

Kreps, D. (1990), 'Corporate Culture and Economic Theory’, pp. 90-116 in J. Alt and K. Shepsle (eds), Perspectives on Positive Political Economy, Cambridge University Press, New York.

Lorell, M., A. Sanders and H. Levaux (1995), Bomber $R$ \& D since 1945: The Role of Experience, RAND, MR-670-AF, 1995. 
Lorell, M., J. Lowell, M. Kennedy and H. Levaux (2000), Cheaper, Faster, Better? Commercial Approaches to Weapons Acquisition, RAND, MR 1147-AF, 2000.

Maskin, E. and C. Xu (2001), Soft Budget Constraint Theories: From Centralization to the Market, CEPR Discussion Paper no. 2715, London.

McNaugher, T. (1989), New Weapons Old Politics: America's Military Procurement Muddle, The Brookings Institution, Washington DC.

Merrow, E., L. McDonwell and R. Arguden (1988), Understanding the Outcomes of Megaprojects: A Quantitative Analysis of Large and Very Large Civilian Projects, Rand Corporation, March, 1988.

Parliament of Australia, Joint Committee of Public Accounts and Audit (1999), Review of Auditor-General's Report No. 34 1997-98, Canberra.

Peck, M. and F. Scherer (1962), The Weapons Acquisition Process: An Economic Analysis, Division of Research, Graduate School of Business Administration, Harvard University, Boston.

Pilling, D. (1989), Competition in Defense Procurement, The Brookings Institution, Washington DC.

President's Blue Ribbon Commission on Defense Management (1986), A Quest for Excellence: Final Report to the President, Government Printing Office, Washington DC.

Riordan, M. (1993), 'Incentives for Cost Reduction in Defense Procurement', pp 135-146 in J. Leitzel and J. Tirole (eds), Incentives in Procurement Contracting, Westview Press, Boulder.

Rogerson, W. (1993), 'Inefficiently Low Production Rates in Defense Procurement: An Economic Analysis', pp 25-39in J. Leitzel and J. Tirole (eds) Incentives in Procurement Contracting, Westview Press, Boulder.

Rogerson, W. (1994), 'Economic Incentives and the Defense Procurement Process', Journal of Economic Perspectives 8(4):65-90.

Williamson, O. (1975), Markets and Hierarchies, The Free Press, Glencoe, Illinois.

All views are personal and not necessarily those of affiliated organisations. We thank two anonymous referees for useful comments. 